\title{
Vernal Keratoconjunctivitis in Public Primary School Children in Nigeria: Prevalence and Nomenclature
}

\author{
Roseline E. Duke, ${ }^{1}$ Friday Odey, ${ }^{2}$ and Stefan De Smedt ${ }^{3}$ \\ ${ }^{1}$ University of Calabar Teaching Hospital, Calabar Children's Eye Center, Department of Ophthalmology, Calabar, \\ Cross River State, Nigeria \\ ${ }^{2}$ University of Calabar Teaching Hospital, Department of Pediatrics, Calabar, Cross River State, Nigeria \\ ${ }^{3}$ Department of Ophthalmology, AZ Sint-Maarten Hospital, Mechelen, Belgium
}

Correspondence should be addressed to Roseline E. Duke; dr.roselineduke@gmail.com

Received 18 March 2016; Accepted 21 June 2016

Academic Editor: Huibert Burger

Copyright (C) 2016 Roseline E. Duke et al. This is an open access article distributed under the Creative Commons Attribution License, which permits unrestricted use, distribution, and reproduction in any medium, provided the original work is properly cited.

\begin{abstract}
Objective. This study sought to add to the body of information on the prevalence and pattern of vernal keratoconjunctivitis (VKC) among school aged children in Cross River State, Nigeria. Method. A cross-sectional survey of children in public primary schools in Cross River State, Nigeria, was studied for VKC. Five schools were included, using a multistage sampling technique. Comprehensive eye examinations were conducted in one thousand two hundred and twenty-six (1226) school children. Main Outcome Measures/Results. The mean age of the population of 1226 school attending children was $9.62 \pm 2.324$. The prevalence of VKC was $18.1 \%$ in this population study. The ratio of males to females is $1.8: 1$. The clinical grading of the 223 children with VKC is as follows: $43(19.3 \%)$ quiescent, $134(60.1 \%)$ mild, 44 (19.7\%) moderate, and $2(0.9 \%)$ severe VKC. The clinical types reported are as follows: limbal $67(30.0 \%)$, tarsal $105(47.1 \%)$, and mixed 51 (22.9\%). The clinical types were used to describe a modified nomenclature. Conclusions. Vernal keratoconjunctivitis is a commonly occurring chronic condition and an important public health problem. A simple diagnostic nomenclature for describing VKC for primary health care workers is recommended.
\end{abstract}

\section{Introduction}

Vernal keratoconjunctivitis (VKC) is an important public health problem especially in the hot and dry regions in Africa $[1,2]$. It is a chronic allergic eye disease that occurs predominantly in children and is responsible for causing moderate-to-severe visual impairment in children. Tremendous progress has been made in combatting measles, vitamin A deficiency, and ophthalmia neonatorum in some lower and middle income countries in the last decades, so that these conditions are no longer regarded as leading causes of corneal blindness in this part of the world $[1,3,4]$. Other conditions such as VKC are becoming a more important cause of corneal visual impairment and blindness [2]. Although rare in temperate regions VKC represents an important cause of hospital referral in many parts of Africa and Asia including Nigerian children [5-7]. A prevalence between 2 and 6\% is reported in various parts of Africa [8]. It was identified as the most common conjunctival disease in children seen in hospitals and school children in Nigeria [5, 8]. Furthermore, VKC is reported to be responsible for the highest percentage (21.0\%) of general eye clinic attending children in Africa and a cause of school nonattendance $[6,9]$. The clinical course of this disease is usually benign and self-limiting, with vision in most children normal, but a group of patients in about $10 \%$ of cases will face very debilitating and sight threatening complications which may sometimes manifest in adulthood and cause blindness as well as visual impairment $[2,10]$. In addition, the quality of life of afflicted children is affected because they are limited in doing their preferred activities, in the attempt to avoid worsening of their disease [11].

Because of these risks it is important to diagnose and manage VKC correctly at the primary eye care level already by using a more practical classification of the disease [2].

This study sought to determine the prevalence and pattern of VKC among public primary school children in Cross 
River State, Nigeria, and to develop a classification of VKC suitable in primary health care settings.

\section{Method}

2.1. Study Setting. The study was conducted in Calabar South Local Government Area (LGA), one of the 18 LGAs in Cross River State, Nigeria, between September and December 2014 in the early dry season. It has an area of $264 \mathrm{~km}^{2}$, a density of 725.4 inhabitants $/ \mathrm{km}$, and a population of 191,630 [12]. Calabar South is located within longitudes $8^{\circ} 15^{\prime}$ East and $8^{\circ} 25^{\prime}$ East and latitudes $4^{\circ} 54^{\prime}$ North and $4^{\circ} 58^{\prime}$ North. Cross River State belongs to tropical rainfall belt where rainfall is usually seasonal and at times very heavy, ranging from $1300 \mathrm{~mm} / \mathrm{sqm}$ to $3000 \mathrm{~mm} / \mathrm{sqm}$. Calabar South records an average annual rainfall amount of $3000 \mathrm{~mm}$ and relative humidity of above $85 \%$ [13]. Mean annual temperature of $30^{\circ} \mathrm{C}$ prevails over Cross River State, except on the Obudu Plateau, where the climate is subtemperate, with temperatures ranging from $15^{\circ} \mathrm{C}$ to $23^{\circ} \mathrm{C}$. The vegetation ranges from mangrove swamps, through rainforest, to derived savannah and mountain parkland. The area is characterized by double maxima rainfall that climaxes in the months of July and September.

The people of Calabar South Local Government Area are predominantly fishermen/women, farmers, petty traders, and canoe carvers and it is the most densely populated and poor area in the southern senatorial district of the state. English is the lingua franca, as this was one of the early British colonized areas of the state. In addition the Calabar South Local Government Area has residents from neighboring states living in the area (Calabar South Local Government Area). Primary school education is considered free in Cross River State; therefore it is expected that primary school children in this population will be included in eye examinations conducted in schools. There are 21 public primary schools within the LGA which have one to six arms. In Calabar South Local Government Area there are 11 primary health centres, 6 health posts, 1 general eye clinic, and a tertiary child eye care facility. There is the Cross River State eye care service including an active child eye care program.

2.2. Study Population. The study population were public primary school attending pupils in Calabar South Local Government Area of Cross River State. The inclusion criteria were children aged 4 years to 15 years in public primary schools and children who did not attend school on the day of examination for any reason. Exclusion criteria were other causes of allergic conjunctivitis. Vernal keratoconjunctivitis was differentiated from the milder forms of allergic eye disease, that is, seasonal allergic conjunctivitis (SAC) and perennial allergic conjunctivitis (PAC), by the presence of limbal and/or giant tarsal papillae. This differentiated VKC from atopic keratoconjunctivitis (AKC) happens more in an older age group and was differentiated from VKC history of atopy in the face and elbows using the Hanifin and Rajka Diagnostic Criteria for Atopic Dermatitis (AD).

The study design was cross-sectional.
2.3. Sample Size Calculation. The sample size calculation for a single proportion where the population is $>10,000$ gave a total sample for the cross-sectional study as 1,500 children in five schools. This was calculated thus: the standard normal deviate of 1.96 was used, with a prevalence of outcome of interest (VKC) as 3\% and a level of precision of 5\%. The nonresponse rate was set at $10 \%$. These resulted in a sample size calculation of 50 children per class. For public schools where there are six class sets, a total of 300 children were seen per school. The sampling frame was composed of a list of all public primary schools in the Calabar South Local Government Area as well as a list of the children registered in the primary school classes. Some of the children that did not attend school on the day of the visit were traced and visited. Parents were invited on the day for the school visit to be interviewed. An informed consent was taken from parents/guardians.

2.4. Sampling Method. Multistage sampling method was used to recruit participants for the proposed study in public school facilities in Calabar South Local Government Area. There are 21 primary schools in Calabar South Local Government Area. In the first stage five public primary schools were randomly selected by balloting from the list of 21 schools. In the second stage, simple random sampling method (through balloting) was used to select the classes in the chosen schools. With the use of an existing register from the selected schools, class sets were used from primary one (1) through primary six (6) to select the 6 classes to be used for the study. For recruitment of children into the study, systematic random sampling was used to select 50 children per class if the number of children was more than 50, leading to the recruitment of 300 students per school. The identity of each child was cross-checked against the class register which is in the custody of the class teacher. Cases of VKC were sought and identified within the targeted population of 1500 children. We also traced some children who were not in school on the day of the examination and whose home we could access.

\subsection{Interview and Examination of All Children}

Demographic and Clinical Data Collected. Parents/caregivers were interviewed and eye examinations were conducted on every child, by the research team that included an ophthalmic nurse, optometrist, and ophthalmologist. Demographic data included school information (name and address of school, class teachers name, class arm, and environmental temperature on day of school visit); pupil demography (name and unique ID of child, age, gender, tribe, address, who the parent lives with, religion, school grade, number of siblings, pupil position in family, siblings with similar problems, parents with similar problems, father and mother's income and occupation, and if they have a mobile phone). Clinical data collected include detailed ocular and systemic history, anthropometric measurements, dermatological examinations, respiratory examinations, vision assessment, autorefraction, Placido's disc, eyelid, tear assessment, conjunctiva, cornea with fluorescein dye, and lens and optic nerve assessment. All examinations were conducted by the same ophthalmologist reducing interobserver error. 
2.6. Operational Definition. Vernal eye disease was defined as the spectrum of tarsal, limbal, and mixed vernal keratoconjunctivitis. It is equivalent to the term VKC as used in other studies. Vernal conjunctivitis (VC) is defined as the presence of conjunctival papillae of $>1 \mathrm{~mm}$ diameter over the upper tarsal plate. It is equivalent to the type tarsal vernal. Vernal keratoconjunctivitis (VKC) is defined as the presence of conjunctival papillae of $>1 \mathrm{~mm}$ diameter over the upper tarsal plate in addition to limbal papillae with or without the presence of Trantas dots. It is equivalent to the type mixed vernal in other studies. Vernal limbitis (VL) is defined as the absence of conjunctival papillae of $>1 \mathrm{~mm}$ diameter over the upper tarsal plate and compulsorily limbal papillae. It is equivalent to the type limbal vernal. Severe vernal keratoconjunctivitis (SVKC) was diagnosed if children have persistent symptoms and signs (diffuse palpebral conjunctival edema; thickening with papillary hypertrophy; giant papillary conjunctivitis; and limbal infiltration of 180 or more). Clinical grading was according to that described by Bonini et al. [14]. At each school visit the Nigeria Meteorological Agency recorded daily forecast of temperature was documented and expressed in degrees centigrade.

2.7. Data Management or Analysis. Data was entered into a Microsoft Excel sheet and analyzed using the Statistical Package for the Social Sciences (SPSS) for Windows (version 20, SPSS Inc., Chicago, IL, USA). Descriptive statistics (frequencies, proportions, means, and standard deviation) was used to summarize the variables, while inferential statistics (chi-square test and Pearson's correlation coefficient for measure of associations and correlation) was applied to test the significant association between categorical variables. At a confidence level of $95 \%$, the level of significance was set at $P<0.05$.

\section{Results}

A total of 1500 children were expected to be investigated in 5 public primary schools.

One hundred and twenty-three (8.2\%) children were registered in the schools but not present in the schools on the days of examination. Eight children of them could be traced to their homes. These children did not have VKC and were absent from school for family reasons. The remaining missing children could not be traced due to logistic challenges. One hundred and fifty-one (151) parents/caregivers were not available to give informed consent. Therefore a total of 1226 children (1218 children in addition to the 8 children found at home) were interviewed and examined comprehensively. Table 1 shows the demography of the general population of children and the VKC population studied.

3.1. Prevalence. VKC was seen in 223 children, resulting in a prevalence of $18.1 \%$. Males accounted for $145(65 \%)$ and females 78 (35\%). The mean ages were $9.3 \pm 2.39$ and $9.32 \pm 2.12$ for males and females, respectively, which was not statistically significant $(P=0.094)$. The ratio of males to females is $1.8: 1$. This was also not statistically significant $(P=0.166)$. Table 1 shows the age and gender distribution.
TABLE 1: Age and gender distribution in the general school and VKC populations.

\begin{tabular}{|c|c|c|}
\hline Age range (yrs)/gender & Frequency & Percent (100) \\
\hline \multicolumn{3}{|l|}{ Age } \\
\hline \multicolumn{3}{|l|}{ General population } \\
\hline $1-5$ & 13 & 1.1 \\
\hline $6-10$ & 809 & 66.0 \\
\hline $11-15$ & 404 & 33.9 \\
\hline Total & 1226 & 100 \\
\hline Mean age & \multicolumn{2}{|c|}{$9.62 \pm 2.324$} \\
\hline \multicolumn{3}{|l|}{ VKC population } \\
\hline $1-5$ & 7 & 3.1 \\
\hline $6-10$ & 156 & 70 \\
\hline $11-15$ & 60 & 26.9 \\
\hline Total & 223 & 100 \\
\hline \multicolumn{3}{|l|}{ Mean age } \\
\hline Males & \multicolumn{2}{|c|}{$9.3 \pm 2.39$} \\
\hline Female & \multicolumn{2}{|c|}{$9.32 \pm 2.12$} \\
\hline \multicolumn{3}{|l|}{ Gender } \\
\hline \multicolumn{3}{|l|}{ General population } \\
\hline Male & 638 & 52 \\
\hline Female & 588 & 48 \\
\hline Total & 1226 & 100.0 \\
\hline \multicolumn{3}{|l|}{ VKC population } \\
\hline Male & 145 & 65 \\
\hline Female & 78 & 35 \\
\hline Total & 223 & 100 \\
\hline
\end{tabular}

3.2. Grade, Clinical Types, and Suggested Nomenclature. The grading of vernal keratoconjunctivitis is described in Table 2. There was a general reduction in the frequency of VKC as the primary school class of the child increased; this appeared to be a trend. Table 3 shows the clinical types of VKC and suggested diagnostic nomenclature. The relationship between the frequency of diagnosis of VKC and the environmental temperature at the school on the day of examination is reported in Table 4 . There was a significant increase in the frequency of diagnosis of VKC as environmental temperature increased $(P<0.001)$.

\section{Discussion}

VKC is a common recurrent bilateral allergic ocular inflammation in which IgE mediated mechanism plays a role affecting children and young adults in their first two decades.

Information on VKC in several countries including Nigeria has been based mainly on hospital data. Most hospital studies show a prevalence between 2 and $6 \%[5,6]$ among patients of all ages. Our study found a population VKCprevalence of $18.1 \%$ among primary school children (please see Table 1). This is much higher than the prevalence (4-5\%) reported by the few available population-based studies with similar design from Africa $[15,16]$. Our study prevalence may be higher because of the population-based study design, with minimal selection bias. In addition, quiescent (19.3\%) and 
TABLE 2: Clinical grading of vernal keratoconjunctivitis [14].

\begin{tabular}{lcc}
\hline Clinical grade & Left eye & Right eye \\
\hline $\begin{array}{l}\text { O (quiescent): absence of } \\
\text { symptoms }\end{array}$ & $43(19.3)$ & $43(19.3)$ \\
\hline $\begin{array}{l}\text { 1 (mild): presence of symptoms } \\
\text { with no corneal involvement }\end{array}$ & $134(60.1)$ & $136(61.0)$ \\
\hline $\begin{array}{l}\text { 2 (moderate): presence of } \\
\text { symptoms + photophobia with } \\
\text { no corneal involvement }\end{array}$ & $44(19.7)$ & $42(18.8)$ \\
\hline $\begin{array}{l}\text { 3 (severe): presence of symptoms } \\
+ \text { photophobia mild-to-moderate } \\
\text { superficial punctate } \\
\text { keratopathy/corneal involvement }\end{array}$ & $2(0.9)$ & $2(0.9)$ \\
$\begin{array}{l}4 \text { (very severe): presence of } \\
\text { symptoms + photophobia }+ \\
\text { diffuse superficial punctate } \\
\text { keratopathy/corneal ulcer }\end{array}$ & $0(0.0)$ & $0(0.0)$ \\
\hline \begin{tabular}{l} 
Total \\
\hline
\end{tabular} & $223(100.0)$ & $223(100.0)$ \\
\hline
\end{tabular}

TABLE 3: Clinical types of VKC and new diagnostic nomenclature.

\begin{tabular}{lcc}
\hline Clinical type of VKC & New diagnostic nomenclature & Number (\%) \\
\hline $\begin{array}{l}\text { Limbal } \\
\text { Tarsal }\end{array}$ & Vernal limbitis & $67(30.0)$ \\
Mixed & Vernal conjunctivitis & $105(47.1)$ \\
\hline Total & Vernal keratoconjunctivitis & $51(22.9)$ \\
\hline $\begin{array}{l}\text { Current name of eye } \\
\text { condition }\end{array}$ & New name for eye condition \\
$\begin{array}{l}\text { Vernal } \\
\text { keratoconjunctivitis }\end{array}$ & \multicolumn{2}{c}{ Vernal eye disease } \\
\hline
\end{tabular}

mild (60.1\%) cases of VKC were included in the study as this is what was seen in the population during the duration and season of the study (Table 2). These grades are reported as having been very common [17]. Moreover, to further explain our high prevalence, it is reported that the incidence of ocular allergy which will affect a prevalence report is underreported [18]. Furthermore, parents are most unlikely to take their children to a hospital for quiescent and mild cases of VKC. Therefore these grades of VKC will go unaccounted for in hospital data. Like a similar study from Rwanda, our study described VKC as it presents itself in the population [9], which has the $0-14$-year age range constituting $42 \%$ of the population [19].

Though there was no statistical significance in the gender, more males were clinically affected. Our study corroborates the information that males are said to be more affected. This follows the general pattern seen in Nigeria as well as in some countries $[13,20,21]$. The onset of VKC is usually after the age of 5 years; the condition eventually resolves around puberty, only rarely persisting beyond the age of 25 years [10].

The diagnosis of VKC is usually made on clinical examination, based on the patient's history and the presence of typical clinical signs and symptoms [14]. The main symptoms include intense ocular itching which may be associated with lacrimation, photophobia, foreign body sensation, and burning. Thick mucus discharge from the eyes and eyelid dropping also occur. The symptoms may occur throughout the year but are characteristically worse during the dry season. In this study the most common clinical type was the tarsal type of VKC. Palpebral forms are said to be more prevalent in Europe and the Americas, whereas mixed and limbal forms are more seen in Asia and Africa, respectively, with some geographic variation and probably hospital attending bias [15].

A tailored approach has earlier been recommended for the treatment of VKC [22]. The diagnosis VKC currently refers to all the three clinical types presently described in literature. Even though the name VKC implies all cases of the disease having corneal involvement, the situation is not so in most cases especially in the quiescent and mild cases. A simple was to understand and practice diagnostic nomenclature for VKC is suggested (please see Table 4). Such a simple classification as we propose could easily guide primary care workers, in the clinical management including treatment decision on the use of steroids in VKC. This new classification allows a swift diagnosis, correct therapy, and evaluation of the prognosis in VKC. Further, this classification may also reflect the onset and the potential for progression of the disease as the years go by, with the disease evolving to a persistent chronic sight threatening condition different from the innocuous mild or quiescent disease [10]. In summary, this new diagnostic classification identifies different clinical entities with different referral criteria and possible clinical outcome. It is also suggested that vernal eye disease could refer to the entire spectrum of the clinical types and replace the term vernal keratoconjunctivitis as presently called which refers to tarsal, limbal, and mixed VKC. Further, vernal conjunctivitis (VC) is defined as the presence of conjunctival papillae of $>1 \mathrm{~mm}$ diameter over the upper tarsal plate. It is equivalent to the type tarsal vernal.

Vernal keratoconjunctivitis (VKC) is defined as the presence of conjunctival papillae of $>1 \mathrm{~mm}$ diameter over the upper tarsal plate in addition to limbal papillae with or without the presence of Trantas dots. It is equivalent to the mixed type. Vernal limbitis (VL) is defined as the absence of conjunctival papillae of $>1 \mathrm{~mm}$ diameter over the upper tarsal plate and compulsorily limbal papillae or Trantas dot. It is equivalent to the type limbal of VKC. In order for VKC to be managed at the primary eye care level, the diagnosis should be unambiguous and the clinical description may need to be matched with treatment modalities and referral criteria.

Various risk factors for the development of VKC have been investigated and reported $[2,10]$. These include ocular, endocrine, genetic, neurogenic, hot dry climate, and high socioeconomic status ones as risk factors. It has been reported that VKC may be seen all year round; however, hot climates predispose to VKC [15]. Further, it is reported by Bonini et al. that about $23 \%$ of patients have a perennial form of VKC from onset and more than $60 \%$ have additional recurrences [10]. This study was conducted during the first half of the dry season different from a similar study which was conducted during the second half of the dry season [15]. The catalyst for progression to more severe disease as well as the occurrence of exacerbations is still to be well 
TABLE 4: Relationship between primary school, environmental temperature, and clinical type of vernal keratoconjunctivitis.

\begin{tabular}{|c|c|c|c|c|c|c|}
\hline \multirow{2}{*}{ School/temp ${ }^{\circ} \mathrm{C}$} & \multicolumn{4}{|c|}{ Clinical types of vernal keratoconjunctivitis } & \multirow{2}{*}{ Chi-square } & \multirow{2}{*}{$P$ value } \\
\hline & Limbal & Tarsal & Mixed & Total & & \\
\hline GPSMA/27 & $5(38.8)$ & $24(22.9)$ & $12(23.5)$ & $41(18.4)$ & 33.928 & $<0.001^{*}$ \\
\hline ECPS/30 & $26(38.8)$ & $8(7.6)$ & $12(23.5)$ & $46(20.6)$ & & \\
\hline GPSA/29 & $13(19.4)$ & $23(21.9)$ & $10(19.6)$ & $46(20.6)$ & & \\
\hline HTPS/34 & $16(23.9)$ & $43(41.0)$ & $12(23.5)$ & $71(31.8)$ & & \\
\hline LPS/23 & $7(10.4)$ & $7(6.7)$ & $5(9.8)$ & $19(8.5)$ & & \\
\hline
\end{tabular}

${ }^{*}$ Statistically significant; GPSMA = Government Primary School, Mayne Avenue; ECPS = Emmanuel Church Primary School; GPSA = Government Primary School Academy; HTPS = Holy Trinity Primary School; LPS = Lutheran Primary School.

defined; however, suggested causes of exacerbation are said to be from allergenic reexposure and/or sunlight, wind, and dust $[23,24]$. Even though the average temperature for the day was not taken, but rather the temperature at the time of eye examinations, this measure when aggregated from different schools visited suggests that we can have a representative idea of the trend with temperature (Table 4). Furthermore, it suggests that as the dry season progresses with increasing temperature one may likely see a rise in case presentations of VKC. Our study therefore tends to support the fact that there may be seasonality and that a progressive increase in environmental temperature in a hot and dry climate may be one factor that encourages exacerbation of disease especially in the limbal type. This is consistent with other series from Africa which report seasonal variation in severity in up to $40 \%$ of patients with VKC [7], further suggesting that some of the mild cases of VKC may become moderate or severe enough to present to hospital later as the environmental temperature increases. Nevertheless, the aetiology and pathophysiology of $\mathrm{VKC}$ and predisposing risk factors for visual impairment still remain unclear.

Some limitations of the study include the fact that eye examination was done by only one ophthalmologist without corroboration by another independent clinician. This is important since diagnosis of $\mathrm{VKC}$ is clinical and there are other diseases within the group of allergic conjunctivitis diseases such as perennial and seasonal conjunctivitis, rhinoconjunctivitis, atopic keratoconjunctivitis, and giant papillary conjunctivitis [10]. However, this is a common clinical condition with characteristic features in this environment; therefore missing a diagnosis is most unlikely. Obtaining sociodemographic information from parents and guardians including consent may have been hampered by traditional beliefs. Lastly, only $80 \%$ of the targeted population was studied which is a limitation of the study. Some of the children who could not be visited in their homes and who had dropped out of school may have had VKC. This group of people have been seen to have a high incidence of VKC and it is a cause of school nonattendance [9]; such children were not represented in this study.

In conclusion, this population-based study which estimates the probability of the children being affected by VKC at this point in time shows a high prevalence and also gives an idea of the burden of this chronic disease and the implication for health services. This affirms alongside other studies that VKC is an important public health problem in Nigeria. A modified simple and practical diagnostic nomenclature is suggested for use by primary health care workers.

\section{Ethical Approval}

Ethical approval was obtained from the Cross River State Ministry of Health Ethical Review Board and the study was conducted in accordance with the Declaration of Helsinki.

\section{Competing Interests}

The authors declare that they have no competing interests.

\section{References}

[1] R. Duke, E. Otong, M. Iso et al., "Using key informants to estimate prevalence of severe visual impairment and blindness in children in Cross River State, Nigeria," Journal of AAPOS, vol. 17, no. 4, pp. 381-384, 2013.

[2] S. De Smedt, G. Wildner, and P. Kestelyn, "Vernal keratoconjunctivitis: an update," British Journal of Ophthalmology, vol. 97, no. 1, pp. 9-14, 2013.

[3] C. Gilbert and A. Foster, "Childhood blindness in the context of VISION 2020: the right to sight," Bulletin of the World Health Organization, vol. 79, no. 3, pp. 227-232, 2001.

[4] P. Gogate, K. Kalua, and P. Courtright, "Blindness in childhood in developing countries: time for a reassessment?" PLoS Medicine, vol. 6, no. 12, Article ID e1000177, 2009.

[5] C. U. Ukponmwan, "Vernal keratoconjunctivitis in Nigerians: 109 consecutive cases," Tropical Doctor, vol. 33, no. 4, pp. 242245, 2003.

[6] R. Duke, "Pediatric eye care: common causes of blindness and visual impairment in children in a hospital setting," Mary Slessor Journal of Medicine, vol. 9, no. 2, pp. 63-67, 2009.

[7] J. H. Sandford-Smith, "Vernal eye disease in Northern Nigeria," Tropical and Geographical Medicine, vol. 31, no. 3, pp. 321-328, 1979.

[8] A. I. Ajaiyeoba, "Prevalence of atopic diseases in Nigerian children with vernal kerato-conjunctivitis," West African Journal of Medicine, vol. 22, no. 1, pp. 15-17, 2003.

[9] S. K. De Smedt, J. Nkurikiye, Y. S. Fonteyne, S. J. Tuft, C. E. Gilbert, and P. Kestelyn, "Vernal keratoconjunctivitis in school children in Rwanda: clinical presentation, impact on school attendance, and access to medical care," Ophthalmology, vol. 119, no. 9, pp. 1766-1772, 2012.

[10] S. Bonini, M. Coassin, S. Aronni, and A. Lambiase, "Vernal keratoconjunctivitis," Eye, vol. 18, no. 4, pp. 345-351, 2004. 
[11] M. Sacchetti, I. Baiardini, A. Lambiase et al., "Development and testing of the quality of life in children with vernal keratoconjunctivitis questionnaire," American Journal of Ophthalmology, vol. 144, no. 4, pp. 557-563.e2, 2007.

[12] Nigerian National Population Gazett, Clan Edict Formation, 1st edition, 1976.

[13] D. I. Eni and J. Efiong, "Seasonal variation in hydrochemical parameters of ground water in calabar soyth, Cross River State, Nigeria," British Journal of Arts and Social Sciences, vol. 3, no. 1, pp. 2046-9578, 2011.

[14] S. Bonini, M. Sacchetti, F. Mantelli, and A. Lambiase, "Clinical grading of vernal keratoconjunctivitis," Current Opinion in Allergy and Clinical Immunology, vol. 7, no. 5, pp. 436-441, 2007.

[15] S. De Smedt, J. Nkurikiye, Y. Fonteyne et al., "Vernal keratoconjunctivitis in school children in Rwanda and its association with socio-economic status: a population-based survey," The American Journal of Tropical Medicine and Hygiene, vol. 85, no. 4, pp. 711-717, 2011.

[16] S. Resnikoff, G. Cornand, G. Filliard, and L. Hugard, "Limbal vernal conjunctivitis in the tropics," Revue Internationale $d u$ Trachome, vol. 3-4, pp. 53-71, 1988.

[17] A. Lambiase, S. Minchiotti, A. Leonardi et al., "Prospective, multicenter demographic and epidemiological study on vernal keratoconjunctivitis: a glimpse of ocular surface in Italian population," Ophthalmic Epidemiology, vol. 16, no. 1, pp. 38-41, 2009.

[18] A. Leonardi, F. Busca, L. Motterle et al., "Case series of 406 vernal keratoconjunctivitis patients: a demographic and epidemiological study," Acta Ophthalmologica Scandinavica, vol. 84, no. 3, pp. 406-410, 2006.

[19] E. J. Aniah and P. B. Utang, "Population structure: educational facilities and environmental implications in the Cross River Region, Nigeria," Global Journal of Social Sciences, vol. 3, no. 1-2, pp. 47-51, 2004.

[20] E. N. Onwasigwe, R. E. Umeh, N. O. Magulike, and C. N. Onwasigwe, "Vernal conjunctivitis in Nigeria children," Orient Journal of Medicine, vol. 6, pp. 21-23, 1994.

[21] S. Majekodunmi, "Vernal conjunctivitis in Nigerian children," Journal of Pediatric Ophthalmology and Strabismus, vol. 15, no. 3, pp. 176-178, 1978.

[22] M. Sacchetti, A. Lambiase, F. Mantelli, V. Deligianni, A. Leonardi, and S. Bonini, "Tailored approach to the treatment of vernal keratoconjunctivitis,” Ophthalmology, vol. 117, no. 7, pp. 1294-1299, 2010.

[23] A. Leonardi, "Allergy and allergic mediators in tears," Experimental Eye Research, vol. 117, pp. 106-117, 2013.

[24] V. M. Utz and A. R. Kaufman, "Allergic eye disease," Pediatric Clinics of North America, vol. 61, no. 3, pp. 607-620, 2014. 


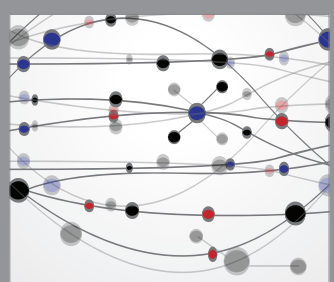

The Scientific World Journal
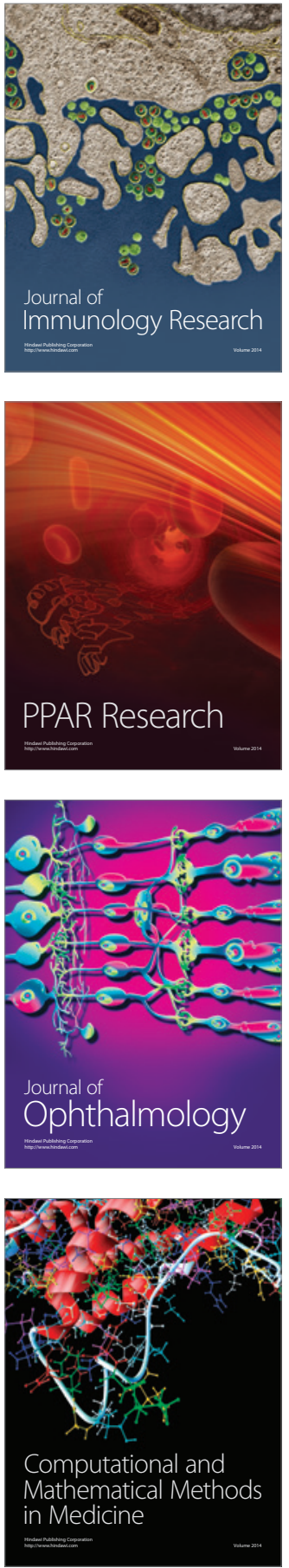

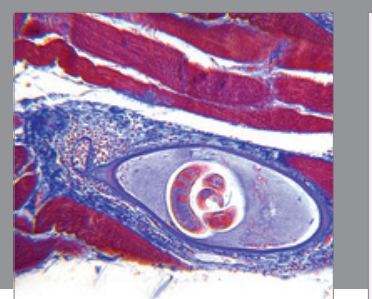

Gastroenterology Research and Practice

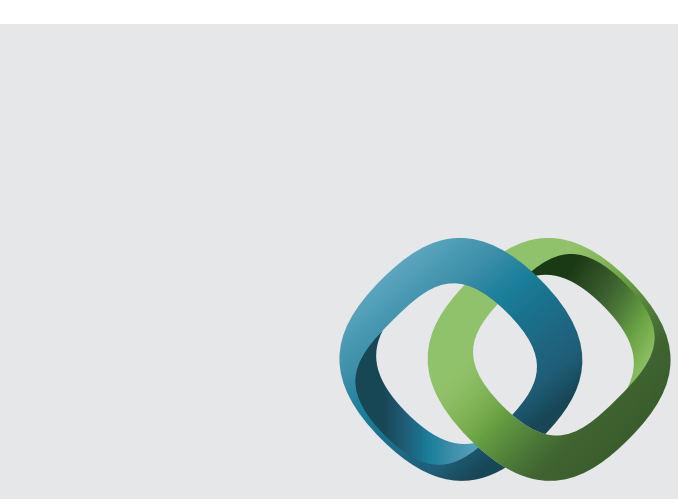

\section{Hindawi}

Submit your manuscripts at

http://www.hindawi.com
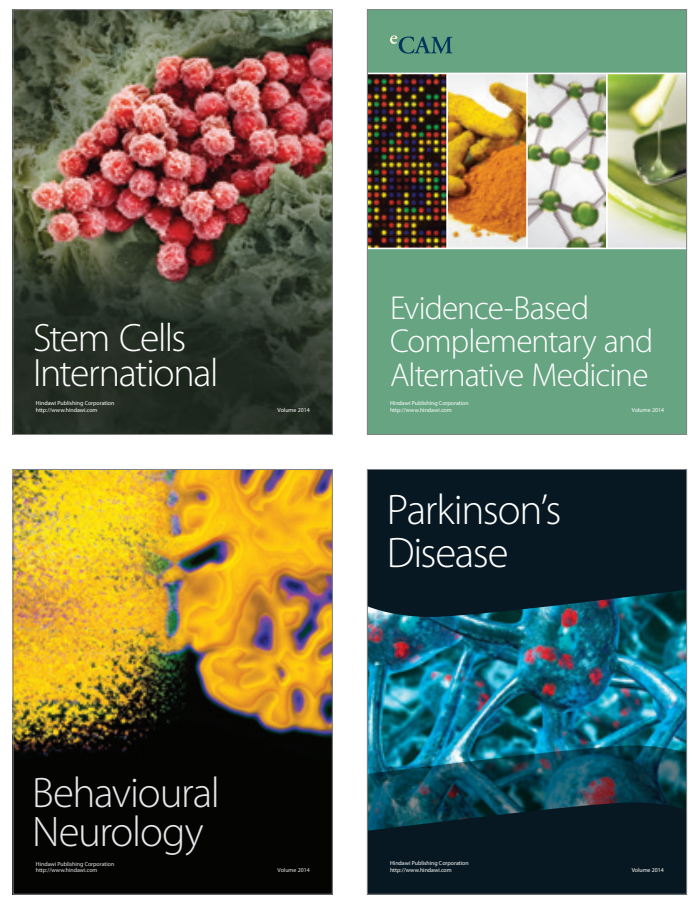
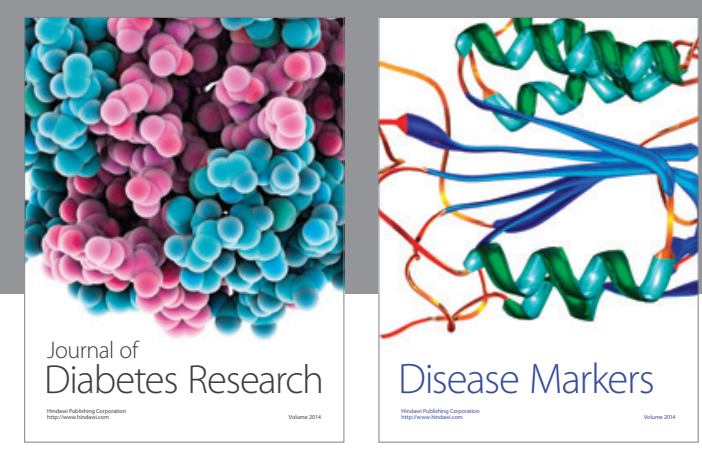

Disease Markers
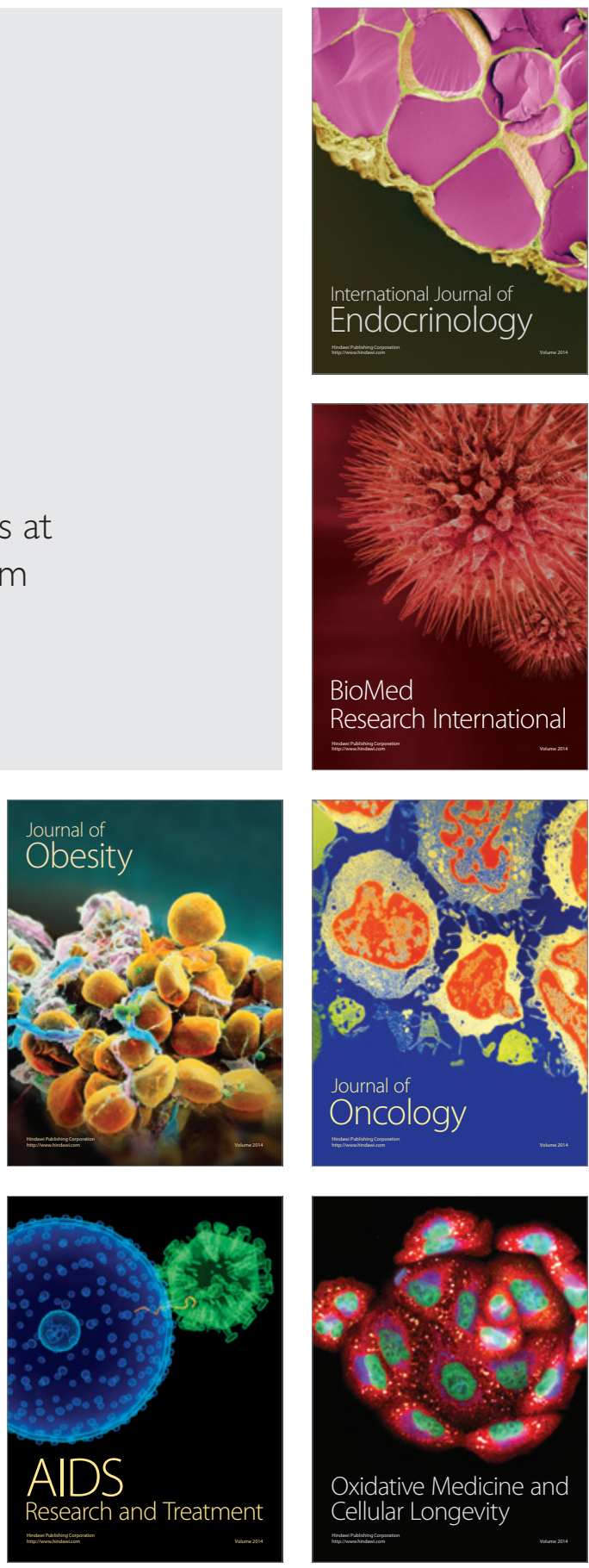